\title{
вмј Global Health Creating the Strategic and Technical Advisory Group of Experts (STAGE) to advance maternal, newborn, child, adolescent health and nutrition: a new approach
}

The Strategic and Technical Advisory Group of Experts

To cite: The Strategic and Technical Advisory Group of Experts. Creating the Strategic and Technical Advisory Group of Experts (STAGE) to advance maternal, newborn, child, adolescent health and nutrition: a new approach. BMJ Global Health 2021;6:e006726. doi:10.1136/ bmjgh-2021-006726

Handling editor Seye Abimbola

Received 25 June 2021 Accepted 27 June 2021

Check for updates

(c) Author(s) (or their employer(s)) 2021. Re-use permitted under CC BY-NC. No commercial re-use. See rights and permissions. Published by BMJ.

Correspondence to The Strategic and Technical Advisory Group of Experts; Caroline.homer@burnet.edu.au

\section{INTRODUCTION}

The Strategic and Technical Advisory Group of Experts (STAGE) for Maternal, Newborn, Child, Adolescent Health and Nutrition (MNCAHN) which advises the DirectorGeneral of WHO, marked its first anniversary in April 2021 as it concluded its third virtual meeting. STAGE has 31 members from all WHO regions and includes the key discipline groups that focus on MNCAHN. STAGE is an independent advisory group that takes a critical look at initiatives and programmes at WHO related to MNCHAN. STAGE provides an opportunity to monitor progress, connect agendas and groups and is a space to facilitate synergies across WHO departments, as well as with other United Nations (UN) agencies.

STAGE was created in response to the global review to improve child survival and health $^{1}$ that highlighted the need for a global expert group to appraise evidence, provide advice on interventions and implementation strategies and improve alignment between global and national stakeholders. This review, along with the Global Strategy for Women's, Children's and Adolescents' Health (2016$2030)^{2}$ articulated the need to address the broader determinants of health, and to move beyond a focus on survival to thrive and transform contributing to the Sustainable Development Goals (SDG). STAGE, while advising and helping $\mathrm{WHO}$, brings together comprehensive and connected perspectives and is committed to making recommendations that support countries and regions. As a global advisory body, the observations and recommendations of STAGE will be relevant not only to WHO but to all partners, including

\section{Summary box}

- The Strategic and Technical Advisory Group of Experts (STAGE) for Maternal, Newborn, Child, Adolescent Health and Nutrition (MNCAHN) was established by the Director-General of WHO in 2020.

- STAGE is an independent advisory group with $31 \mathrm{mem}$ bers. The key role is to provide a critical review of initiatives and programmes at WHO related to MNCHAN, to monitor progress, connect agendas and groups and is a space to facilitate synergies across WHO departments, as well as with other United Nations agencies.

- STAGE was created in response to the global review to improve child survival and health that highlighted the need for a global expert group to appraise evidence, provide advice on interventions and implementation strategies and improve alignment between global and national stakeholders.

- STAGE's recommendations have highlighted the critical importance of sustaining essential services, including MNCAHN, the need to improve the translation of evidence-based guidelines into successful programmes at the country level and the need for evidence-based packages of interventions for maternal and child health along the life course.

- STAGE will continue to advise on priority areas to improve MNCAHN outcomes to achieve the Sustainable Development Goals. STAGE's work will continue to addresses universal health coverage, which been interrupted by the pandemic, and with a clear emphasis on cross-sectoral approaches.

- In the next 2 years, STAGE will narrow its agenda to specific topics where WHO and the global MNCHAN community seek guidance. To support this transition, and ensure its future agenda is responsive to expressed needs, STAGE will global inputs and oversee a prioritisation process.

other UN agencies and donors who can make guided investments.

STAGE was launched in the early months of the COVID-19 pandemic and this has shaped 
much of the discussions. Throughout our meetings, we have recognised the incredible sacrifices being made by health workers around the world, often at considerable personal risk where personal protective equipment, vaccines and care are inadequate. Health workers are striving to deliver critical MNCAHN services despite considerable disruptions which threaten to unravel progress made over the past decade. STAGE recognises that no mother, newborn, child or adolescent is safe until they and the health workers who look after them are safe, including access to vaccines and other tools for infection prevention, as well as safe from violence, burn-out and poor health.

As well as three formal meetings to articulate recommendations, STAGE also established working groups, that met frequently, to enable deeper engagement on specific areas of work. Meetings have actively engaged and co-opted people from WHO headquarters and regional offices and members of non-governmental organisations to explore diverse opinions, prior to finalising STAGE recommendations. In its first year, STAGE provided recommendations on some of the key strategic challenges WHO needs to tackle to improve MNCAHN outcomes including addressing COVID-19 disruptions. As it moves forward, STAGE will narrow its agenda to specific topics where WHO and the global MNCHAN community seek guidance. To support this transition, and ensure its future agenda is responsive to expressed needs, STAGE will seek global inputs and oversee a prioritisation process.

\section{MNCAHN NEEDS IN A PANDEMIC}

STAGE's birth in the context of an unprecedented pandemic revealed the importance of sustaining essential services, including MNCAHN. STAGE recommended strengthening coordination in the measurement of disruption and mitigation efforts to reduce the impact of the pandemic on MNCAHN services. ${ }^{34}$ Facilitating a more effective response for mothers, newborns, children and adolescents at times of shock or crisis situations requires real-time quality data at the country level and this has largely been absent. WHO has provided recent guidance on using routine data to analyse disruption and STAGE further emphasised the need for sustained investment and local ownership, for relevant, robust and reliable health information systems. ${ }^{45}$

Having a critical review of solutions and learning from countries during the pandemic will support resilience against inevitable future disruptions, including the resurgence of COVID-19 infections. STAGE recommended that WHO, with other partners, manage the efforts to optimise research, minimise duplication and advised on the collation and synthesis of the many studies to enhance global knowledge of critical interventions that better anticipate needs and maintain essential MNCAHN services during shocks. ${ }^{3}$ STAGE also highlighted that, without healthcare workers, there will be no recovery, no 'building back better', and the pandemic will lead to a seismic gap in the health workforce.

\section{EVIDENCE TO IMPACT}

STAGE has made key recommendations to improve the translation of evidence-based guidelines into successful programmes at the country level, especially in difficult and resource-constrained environments. ${ }^{4}$ An example of this translation is to support the scale-up of Kangaroo Mother Care (KMC) especially with the release of the findings from the Immediate KMC trial. ${ }^{6}$ STAGE will oversee a working group with wide membership to develop a position paper and implementation strategy to guide the investment and scale-up of $\mathrm{KMC}$ within an integrated maternal and newborn care services approach. ${ }^{3}$ At a broader level, STAGE also recommended that WHO support the formation, or consolidation, of Regional and National Technical Advisory Groups to provide advice based on local epidemiological and equity concerns and monitor the progress of national MNCAHN goals. ${ }^{4}$

\section{MATERNAL AND CHILD HEALTH REDESIGN: TAKING A LIFE- COURSE APPROACH}

The strategic shift from survive to thrive and transform in child and adolescent health, ${ }^{7}$ accompanied by a framework $^{8}$ for interventions at different stages of life, was presented by WHO and approved by STAGE. WHO, in collaboration with UNICEF, will develop evidence-based packages of interventions for maternal and child health along the life course and through platforms which they can be delivered, accompanied by indicators, programme guidance and tools to support implementation. STAGE will regularly review and steer these outputs.

STAGE supported WHO's visionary work with UNESCO to make every school a Health Promoting School. This recognises the untapped potential of schools to promote health and well-being of children and adolescents, as a core consideration within the education process and a measure of performance of national education systems. ${ }^{9}$

\section{CONCLUSION}

In conclusion, STAGE is advising and supporting the Director-General of WHO on priority areas to improve MNCAHN outcomes to achieve the SDGs. STAGE's work will continue to address universal health coverage, which has been interrupted by the pandemic, and we have a clear emphasis on cross-sectoral approaches. However, for STAGE recommendations to have broad and sustained impact requires the commitment of, not only WHO, but all stakeholders including other UN agencies, governments, non-governmental organisations and the private sector.

Acknowledgements Thank you to Dr Anshu Banerjee, Dr Beena Varghese and Dr Tejshri Shah from the WHO for assistance in writing this Commentary.

Collaborators Current STAGE members: Professor Fadia AIBuhairan (Interim Chief Medical Officer, Al Dar Hospital and Medical Center, Riyadh, Kingdom of 
Saudi Arabia), Dr Koki Agarwal (Program Director, USAID Maternal Child Survival Program; Jhpiego, Washington DC, United Sates of America), Dr Narendra Kumar Arora (Executive Director, The INCLEN Trust International, New Delhi, Republic of India), Sir Sabaratnam Arulkumaran (Professor Emeritus in Obstetrics and Gynaecology, St George's University of London, United Kingdom of Great Britain and Northern Ireland), Prof Zulfi Bhutta (Robert Harding Chair in Global Child Health \& Policy; Co-Director, SickKids Centre for Global Child Health; Professor, Departments of Paediatrics, Nutritional Sciences and Public Health, University of Toronto, Toronto, Canada), Prof Fred Binka (Professor of Clinical Epidemiology, University of Health and Allied Sciences (UHAS), Ho, Republic of Ghana), Dr Arachu Castro (Samuel Z. Stone Chair of Public Health in Latin America Department of Global Community Health and Behavioral Sciences Tulane School of Public Health and Tropical Medicine, New Orleans, United States of America), Dr Mariam Claeson (Former Director of the Global Financing Facility for Every Woman Every Child), Dr Blami Dao (Technical Director, Western and Central Africa, Jhpiego, Ouagadougou, Burkina Faso), Dr Gary Darmstadt (Associate Dean for Maternal and Child Health; Professor and Co-Director of Global Pediatric Research, Department of Pediatrics, Stanford University School of Medicine, Stanford, California, United States of America, (Dr Trevor Duke (Professor, Centre for International Child Health, University of Melbourne, Melbourne, Australia) Prof Mike English (Theme Leader, Health Systems Research, \& Head Health Services Unit, KEMRI-Wellcome Trust (KWTRP, Kenya) Professor, International Child Health, University of Oxford, United Kingdom of Great Britain and Northern Ireland), Dr Fadi Jardali (Professor of Health Policy and Systems Department of Health Management and Policy, American University of Beirut, Beirut, Lebanese Republic), Dr Mike Merson (Wolfgang Joklik Professor of Global Health, Duke Global Health Institute, Duke University, Durham, United States of America), Prof Rashida Abbas Ferrand (Professor of International Health, London School of Hygiene \& Tropical Medicine (LSHTM) \& Wellcome Trust Senior Fellow in Clinical Science United Kingdom of Great Britain and Northern Ireland), Dr Alma Golden (Executive Director, Global Development Lab, U.S. Agency for International Development (USAID) Washington, DC, United States of America), Prof Michael Golden (Pollgorm, Ardbane, Downings Letterkenny, Co Donegal, Ireland), Professor Caroline Homer (Co-Program Director, Maternal and Child Health and Working Group Head; NHMRC Principal Research Fellow, Burnet Institute, Melbourne, Australia), Dr Fyezah Jehan (Associate Professor, Dept of Pediatrics and Child Health, Aga Khan University, Karachi, Islamic Republic of Pakistan), Dr Caroline Kabiru (Associate \& Senior Technical Advisor, Evidence to End FGM/C Program, Population Council, Nairobi, Republic of Kenya), Prof Betty Kirkwood (Professor of Epidemiology \& International Health, Faculty of Epidemiology \& Population Health, London School of Hygiene \& Tropical Medicine (LSHTM), London, United Kingdom of Great Britain and Northern Ireland), Prof Joy Lawn (Professor of Epidemiology \& International Health, Faculty of Epidemiology \& Population Health, London School of Hygiene \& Tropical Medicine (LSHTM), London, United Kingdom of Great Britain and Northern Ireland), Dr Song Li (Deputy Director-General, Department of Women \& Children's Health, National Health Commission (NHC), People's Republic of China), Prof George Patton (Professor of Adolescent Health Research, University of Melbourne, Centre for Adolescent Health, Royal Children's Hospital, Victoria, Australia), Dr Marie Ruel (Director, Poverty, Health, and Nutrition Division, International Food Policy Research Institute, Washington, DC, United States of America), Prof Jane Sandall (Professor of Social Science and Women's Health, Department of Women and Children's Health, School of Life Course Science, Faculty of Life Sciences and Medicine King's College, London, United Kingdom of Great Britain and Northern Ireland), Professor Harshpal Singh Sachdev (Senior Consultant Pediatrics and Clinical Epidemiology, Sitaram Bhartia Institute of Science and Research, New Delhi, India), Prof Mark Tomlinson (Professor, Institute for Life Course Health Research, Department of Global Health, Faculty of Medicine and Health Sciences, Stellenbosch University, Cape Town, South Africa, Republic of South Africa), Dr Peter Waiswa (Associate Professor, Dept of Health Policy, Planning and Management, Makerere University School of Public Health, Kampala, Republic of Uganda), Dr Dilys Walker (Professor and Director of the Global Maternal Newborn Child Health Research Group, Institute for Global Health Sciences, University of
California, San Francisco, United States of America),Dr Stanley Zlotkin (Professor of Paediatrics, Public Health Sciences and Nutritional Sciences at the University of Toronto, Canada).

Contributors The authors of this Commentary are all current STAGE member.

Funding The authors have not declared a specific grant for this research from any funding agency in the public, commercial or not-for-profit sectors.

Competing interests None declared.

Patient consent for publication Not required.

Provenance and peer review Not commissioned; internally peer reviewed.

Data availability statement The reports are avaible from: https://www.who.int/ groups/strategic-and-technical-advisory-group-of-experts-for-maternal-newbornchild-and-adolescent-health-and-nutrition

Open access This is an open access article distributed in accordance with the Creative Commons Attribution Non Commercial (CC BY-NC 4.0) license, which permits others to distribute, remix, adapt, build upon this work non-commercially, and license their derivative works on different terms, provided the original work is properly cited, appropriate credit is given, any changes made indicated, and the use is non-commercial. See: http://creativecommons.org/licenses/by-nc/4.0/.

\section{REFERENCES}

1 Costello A, Dalglish S, on behalf of the Strategic Review Study Team. Towards a grand convergence for child survival and health: a strategic review of options for the future building on lessons learnt from IMNCI. Geneva: WHO, 2016.

2 WHO. Global strategy for women's, children's and adolescents health. New York: Every Woman Every Child, 2015.

3 Strategic and Technical Advisory Group of Experts (STAGE). Meeting of the who strategic and technical Advisory group of experts (stage) on MNCAHN, 27-29 April 202 Geneva: World Health organization, 2020. Available: https://www.who.int/news-room/events/detail/2020/ 04/30/default-calendar/inuagural-meeting-of-the-strategic-andtechnical-advisory-group-of-experts-(stage)-for-maternal-newbornchild-and-adolescent-health-and-nutrition-(mncahn) [Accessed 13 Jun 2021].

4 WHO Strategic and Technical Advisory Group of Experts (STAGE). Meeting of the who strategic and technical Advisory group of experts (stage) on MNCAHN, 2-4 nov 2020 Geneva: World Health organization, 2021. Available: https://www.who.int/publications/m/ item/meeting-of-the-who-strategic-and-technical-advisory-group-ofexperts-on-mncahn-2-4-nov-2020 [Accessed 13 Jun 2021].

5 WHO. Analysing and using routine data to monitor the effects of COVID-19 on essential health services: a practical guide for national and subnational decision-makers. Geneva: World Health organization Geneva: World Health organization, 2021. Available: https://www.who. int/publications/i/item/who-2019-nCoV-essential-health-servicesmonitoring-2021-1 [Accessed 13 Jun 2021].

6 WHO Immediate KMC Study Group. Immediate "kangaroo mother care" and survival of infants with low birth weight. N Engl J Med Overseas Ed 2021;384:2028-38.

7 Requejo J, Strong K, Child Health Redesign writing team. Redesigning health programmes for all children and adolescents. BMJ 2021;372:n533.

8 WHO, UNICEF. Investing in our future: a comprehensive agenda for the health and well-being of children and adolescents: working document Geneva: World Health organization, 2020. Available: https://www.who. int/publications/i/item/investing-in-our-future [Accessed 13 Jun 2021].

9 WHO, UNESCO. Global standards for health promoting schools and their implementation guidance Geneva: World Health organization, 2018 Available: https://www.who.int/publications/i/item/global-standards-forhealth-promoting-schools [Accessed 13 Jun 2021]. 